\title{
Solar Variability, Galactic Cosmic Rays and Climate: A Review
}

\author{
A. K. Singh ${ }^{1}$, R. P. Singh ${ }^{2}$ and Devendraa Siingh ${ }^{3}$ \\ ${ }^{1}$ Physics Department, University of Lucknow, Lucknow - 226007, India \\ ${ }^{2}$ Physics Department, Banaras Hindu University, Varanasi - 221005, India \\ ${ }^{3}$ Indian Institute of Tropical Meteorology, Pune-411008, India \\ Email: aksphys@gmail.com
}

\begin{abstract}
Climate is among the most important natural resources for all living beings. The main external and internal driver for climate change is variability of the Sun. The Sun is the ultimate source of the energy on the Earth and play a key role in its climate change. What is still not known and needs to be found is the extent to which these variations in solar behavior affect the total energy that the Sun emits. The small variation in the solar irradiance and changes in its spectral distribution leads to a large variation in climate. An attempt has been made to report the present understanding of the solar variability and its consequences on the variability of solar irradiance which exhibits 11-year cyclic variation and modulation on higher time scale. Galactic Cosmic Rays (GCR) reaching the Earth's atmosphere is modulated by the solar wind and geomagnetic field, which also exhibit 11-year cyclic variation. In the present paper, we have reviewed our current understanding on physics of solar variability, galactic cosmic rays and their effects on the Earth's climate.
\end{abstract}

Keywords: Solar variability; Solar activity; Total solar irradiance; Galactic cosmic rays; Earth's climate

\section{Introduction}

Solar variability, cosmic rays and their effects on the Earth's climate is very common issue to talk these days but their understanding of quantitative and qualitative impacts is still very complex and unexplained phenomena (Reid, 2000; Gray et al., 2010; Usoskin, 2012). The solar variability is caused by solar evolution drive by conditions within the Sun and the magnetic field evolution in the solar convection zone. Various phenomena observed at and above the solar surface such as small flux tube, sunspots, active region, coronal mass ejections and flares, manifest themselves in violent fluctuations in the radiation of ultraviolet (UV) emission lines, the spectral distribution, the total power of broadband electromagnetic emissions as well as in the solar wind and energetic particle fluxes (Frohlich, 2006). The electromagnetic emission of the Sun, therefore, also increases and decreases in a cycle that matches the 11-year cycle of the sunspot count. Surprisingly, visible light emissions from the Sun hardly vary over the course of this cycle; the Sun brightens and dims in the visible light region of the spectrum by only about $0.1 \%$ (Wilson and Hudson, 1991; Weart, 2006). This corresponds to a change in solar insolation at Earth of 1 or $2 \mathrm{~W} / \mathrm{m}^{2}$ out of the 1,368 W/m $\mathrm{m}^{2}$ that reach the top of Earth's atmosphere (Willson and Mordinov, 2003). 
The variation in the terrestrial climate is attributed to the variation in solar energy incident on the Earth's Atmosphere. The dominant energy source for surface heating comes from longwave heating from the atmosphere. About 50\% of energy incident from the Sun is absorbed by the surface and about $30 \%$ is reflected back into the space (Vita-Finzi, 2008). The reflected energy consists of $\sim 20 \%$ by clouds, $6 \%$ by air and $\sim 4 \%$ by the surface. About $16 \%$ is absorbed by the atmosphere (mostly by dust particles in the troposphere). $79 \%$ of the received energy is returned to the atmosphere in the form of thermal radiation and $21 \%$ is transmitted to the atmosphere by conduction through the evaporation of $\mathrm{H}_{2} \mathrm{O}$ leading to the surface cooling (Hanslmeier, 2007). Solar energy variation is also affected by the rotation of the sun and Earth precession and obliquity in Earth's rotational axis and orbital changes due to eccentricity of Earth's orbit. The solar magnetic field associated with solar wind scatters galactic cosmic ray particles in the heliosphere and modulates their incidence at the terrestrial atmosphere. Galactic cosmic rays (GCRs) being high energy particle affect the atmospheric processes including cloud microphysics (Tinsley, 2008; Singh et al., 2011, Siingh et al., 2011). As a result of scattering minimum GCRs reaches at the terrestrial atmosphere during the solar maximum. The lower values of GCRs flux produces smaller amount of ionization in the lower atmosphere which may result into the comparatively smaller amount of ion induced formation of sulphate aerosol which acts as efficient cloud condensation nuclei. This ultimately results into smaller cloud cover and larger surface temperature (Tinsley and Yu, 2003). The other route could be the modification of the vertical current in the global electric circuit which controls the microphysical phenomena of cloud formation (Tinsley, 2008).

All solar fluctuations that disturb the Earth can be traced to the effects of the strong solar magnetic fields that thread their way through the photospheric surface and into the middle and outer atmosphere of the star. The mechanism proposed to explain the climate response to very small solar changes are relatively well advanced, the GCRs cloud mechanisms are little understood and have just began to be quantified. The objective of this paper is to present the current understanding of solar variability, its relation with cosmic rays and overall impact on the climate of terrestrial environment.

\section{Solar Activity and Solar Variability}

Solar activity can have different meanings. It can indicate the intensity of solar electromagnetic radiation, particularly notable at wavelength of solar x-rays and the extreme ultra-violet or it can refers events like coronal mass ejection and solar proton events. The solar atmosphere harbours a broad range of non-thermal phenomena collectively called activity which is responsible for the sharp temperature increase above the solar photosphere. On the local scale it produces a variety of discrete features, including the dark sunspots and bright faculae of the photosphere, the emission plages and network of the chromospheres, and the intricate structures of the solar corona (Radick, 2004). These changes on the solar surface and interior remotely control the Earth's environment in a variety of ways and on many different time scales, through the solar wind which is a mixture of ions and electrons flowing away from the Sun. In fact, the Sun's outer atmosphere is so hot that not even the Sun's gravity can prevent it from continuously evaporating.

The escaping plasma carries the solar magnetic field along with it (Parker, 1957), out to the boundary of the heliosphere where its dominance finally ends (Schwenn, 2006a, b) in the interstellar space. Solar activity also includes phenomena related to solar flares and Coronal Mass Ejections (CMEs), and their recurrence in time and space (Singh and Singh, 
2003; Singh et al., 2010; Siingh et al., 2011). Precision radiometric measurements of the total heat and light and other radiation received from the Sun can be made only from above the Earth's atmosphere. This technically challenging task was initiated on a continuing basis in 1978 and has been sustained since that time by a series of dedicated instruments on different solar spacecraft. Table- 1 summarizes the amount of solar energy received at the Earth due to total irradiance as well as particles.

Table-1: Summary of the amount of solar energy received at the Earth.

\begin{tabular}{|c|c|c|c|c|}
\hline Form & $\begin{array}{l}\text { Total Energy in } \\
\text { Watts per square } \\
\text { meter at the top of } \\
\text { the Atmosphere }\end{array}$ & $\begin{array}{l}\text { Fraction that } \\
\text { reaches the } \\
\text { surface }\end{array}$ & $\begin{array}{l}\text { Fraction of total } \\
\text { energy received }\end{array}$ & Variability \\
\hline $\begin{array}{l}\text { Total } \\
\text { Irradiance }\end{array}$ & $2.23 \times 10^{7^{*}}$ & $60 \%$ & $\sim 100 \%$ & $0.1 \%$ \\
\hline Near infrared & $1.13 \times 10^{7}$ & $55 \%$ & $51 \%$ & $0.05 \%$ \\
\hline Visible & $8.90 \times 10^{6}$ & $75 \%$ & $40 \%$ & $0.1 \%$ \\
\hline Near-ultraviolet & $1.98 \times 10^{6}$ & $40 \%$ & $9 \%$ & $1 \%$ \\
\hline Far-infrared & $4.05 \times 10^{4}$ & $20 \%$ & $0.14 \%$ & $0.1 \%$ \\
\hline Far-ultraviolet & $2.02 \times 10^{3}$ & 0 & $0.01 \%$ & $15 \%$ \\
\hline EUV and $x$-ray & $8.09 \times 10^{2}$ & 0 & $0.005 \%$ & up to $200 \%$ \\
\hline \multicolumn{5}{|l|}{ Particles } \\
\hline Solar protons & 8.09 & negligible & up to $x 100$ & \\
\hline $\begin{array}{l}\text { Solar wind } \\
\text { particles }\end{array}$ & 12.14 & negligible & up to $x 30$ & \\
\hline $\begin{array}{l}\text { Galactic cosmic } \\
\text { rays }\end{array}$ & 0.024 & negligible & $\begin{array}{l}20 \% \text { due to } \\
\text { solar } \\
\text { modulation }\end{array}$ & \\
\hline
\end{tabular}

\section{Solar Activity:}

Solar activity is a general term used to describe the nature and extent of solar magnetic field. The dynamics of sunspot cycle driven by the Sun's rotation (dynamo theory) is based on spin momentum (Juckett, 2000). The orbital angular momentum linked to irregular oscillation of motion of centre of mass of the Sun about the centre of mass of the solar system. Fig. 1 shows the group number sunspot variations for four hundred years from 1610-2010, and the little ice age (LIA) periods. The figure also indicates the Maunder Minimum (MM) and the Dalton Minimum (DM) periods. During the MM period (16451715) sunspot number was almost zero (Eddy, 1976) whereas during the DM period (18051825) some sunspots were observed (Schussler et al. 1997). Table-2 summarizes the major causes of solar activity, their lifetimes and effects on the Earth. 


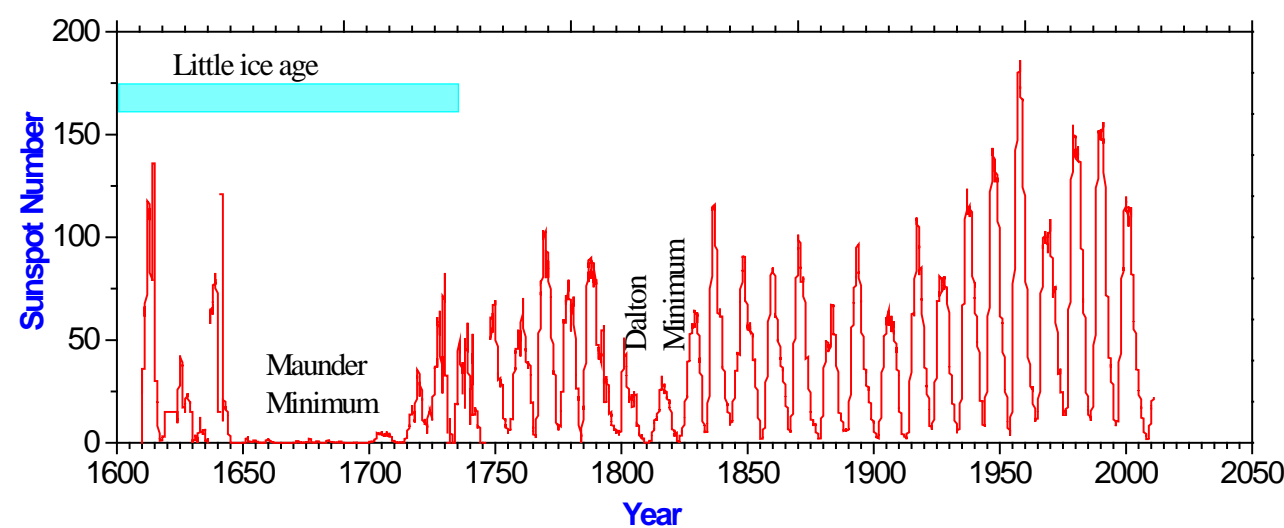

Fig. 1: Variation of the group sunspot number from 1610 to 2010. The gradual increase of solar magnetic activity since the Maunder Minimum is readily apparent (after Siingh et al., 2011).

Table-2: Principal causes of solar activity and their effects on the Earth.

\begin{tabular}{|c|c|c|c|}
\hline Features & Descriptions & Lifetime & Effect on the Earth \\
\hline Sunspots & $\begin{array}{l}\text { Dark spots that appear } \\
\text { on the white-light disk } \\
\text { of the Sun, each the } \\
\text { locus of strong and } \\
\text { concentrated magnetic } \\
\text { flux }\end{array}$ & $\begin{array}{l}\text { Days to a } \\
\text { month or more }\end{array}$ & $\begin{array}{l}\text { Incremental reduction in the total } \\
\text { solar radiation received at the } \\
\text { Earth }\end{array}$ \\
\hline Plages & $\begin{array}{l}\text { Bright patches in the } \\
\text { photosphere and } \\
\text { chromosphere, most } \\
\text { often in association } \\
\text { with sunspots }\end{array}$ & $\begin{array}{l}\text { Days to a } \\
\text { month or more }\end{array}$ & $\begin{array}{l}\text { Incremental increase in the total } \\
\text { solar radiation received at the } \\
\text { Earth }\end{array}$ \\
\hline Flares & $\begin{array}{l}\text { Sudden, explosive } \\
\text { brightening in } \\
\text { magnetically-active } \\
\text { regions in the } \\
\text { chromosphere and } \\
\text { corona, accompanied } \\
\text { by the release of } \\
\text { highly energetic } \\
\text { electromagnetic } \\
\text { radiation and atomic } \\
\text { particles }\end{array}$ & $\begin{array}{l}\text { A few minutes } \\
\text { to an hour or } \\
\text { more }\end{array}$ & $\begin{array}{l}\text { Drastic, transitory increase in the } \\
\text { flux of x-ray and extreme- } \\
\text { ultraviolet radiation with effects } \\
\text { on the upper atmosphere; release } \\
\text { of highly energetic protons, posing } \\
\text { hazards to manned and unmanned } \\
\text { spacecraft and jet aircraft at high } \\
\text { latitudes }\end{array}$ \\
\hline CMEs & $\begin{array}{l}\text { Expulsions of large } \\
\text { segments of the outer } \\
\text { corona, often } \\
\text { becoming larger than } \\
\text { the Sun itself, into } \\
\text { inter-planetary space }\end{array}$ & Days to weeks & $\begin{array}{l}\text { Acceleration of atomic particles in } \\
\text { the solar wind, with concomitant } \\
\text { impacts on the magnetosphere and } \\
\text { upper atmosphere }\end{array}$ \\
\hline
\end{tabular}


The Sun undergoes through various non-stationary and non-equilibrium processes usually called as solar activity contrary to the quiet Sun condition described by simple stellarevolution theories. Solar activity is a consequence of magnetic field that erupts into the atmosphere of the Sun. Solar-surface magnetic variability, eruption phenomena, coronal activity, radiation of the sun as a star or even interplanetary transients and geomagnetic disturbances can be related to the concept of solar activity (Weiss and Tobias, 2000; Usoskin, 2008; Usoskin et al., 2008). A variety of indices quantifying solar activity have been proposed in order to represent different observables and caused effects (Hathaway and Wilson, 2004; Hathaway, 2010). Most of the indices are highly correlated to each other due to the dominant 11-year cycle, but may differ in fine details and/or long-term trends (Ahluwalia and Jackiewicz, 2012). The indices can be roughly divided into physical indices (i.e., those representing real physical quantities measurable for the sun such as radio flux and coronal index and synthetic indices such as solar flare index and sunspot numbers. In addition to the solar indices, there are indirect indices like geomagnetic indices or proxy data is often used to quantify solar activity via its presumably known effect on the magnetosphere or heliosphere (Stuiver and Quay, 1980; Beer et al., 1990; Bard et al., 1997; Beer, 2000).

Modern observations of the Sun provide a vast array of measures of solar activity (Ahluwalia and Jackiewicz, 2012). These observations span the electromagnetic spectrum from radio waves to gamma rays and include particles and plasma waves from the Sun. In addition, we can measure magnetic field on the surface of the Sun and flow fields on the surface and in the interior (Cattaneo, 1999). Many of these observations are more directly related to the sources of solar activity. Understanding the solar activity cycle remains as one of the key problems in solar physics (Ahluwalia and Jackiewicz, 2012). There are two possible mechanisms for reversing the magnetic field that appears in sunspots. The first relies on a self-excited hydromagnetic dynamo in the interior of the Sun, while the second calls for a hydrodynamically driven oscillator. Dynamo action involves the conversion of kinetic energy into magnetic energy by the inductive effects of fluid motion in an electrically conducting fluid, and the dynamo can explain all the relevant observations (Weiss and Tobias, 2000). Although small scale turbulent convection can act as a dynamo and generate a disordered field (Cattaneo, 1999), the systematic behavior of the solar cycle requires a large scale dynamo that relies on rotation to produce an ordered field. The time scales and spatial dimensions of active regions indicate that they rise from deep in the convection zone, and there is a general consequence that the dynamo is located in a region of weak convective overshoot between the radiative and convective zones (Weiss and Tobias, 2000). The last solar cycle apparently lasted for 12.5 years, therefore delaying the buildup of the current cycle, which started with a sunspot, observed on January 4, 2008. This cycle is now picking up with the peak in activity expected in 2013 (Hathaway, 2010). The data from the Solar Dynamics Observatory (SDO) launched on February 11, 2010 into an inclined geosynchronous orbit (Klotz, 2010) may be useful in understanding the cause of solar variability and its impact on the Earth's climate.

Many different indicators have been employed as measure of systematic solar activity. Sunspots are the most obvious magnetic features. The sunspot variation links solar activity and variation in solar radiation (Eddy, 2009). However, the variation in emissions of high energy X-rays and UV radiation is far more dramatic over the course of the solar cycle. In the cycle UV emissions may increase by factors of two to ten, while some X-rays emissions 
increase a hundred-folds. Satellite measurements suggests a decline of $7 \%$ at $200-208 \mathrm{~nm}$ and of 3.5\% at $250 \mathrm{~nm}$ from solar maximum in 1989 to near solar minimum in 1994 (Rottman et al., 1993; Brueckner et al., 1993) which are in agreement with modeled values (Lean, 1997). This spectral variation complicates the issue of climate variation by modifying climate related atmospheric processes at different height, latitude and longitude.

\section{Solar Variability:}

The variation of solar energy incident on the Earth's atmosphere depends on solar activity, which varies on time scales from hours to billions of years, and depends on various processes operating inside/on the surface of the Sun (Eddy, 2009; White et al., 2011). It is also affected by the rotation of the Sun, the precession of the Earth and the obliquity of the Earth's rotational axis and changes due to the eccentricity of Earth's orbit (Berger at al., 2003). The Sun's magnetic field varies in a complex manner, including the well known sunspot cycle of $\sim 11$ years periodicity and longer period modulations. The total solar irradiance which is defined as the total electromagnetic power per unit area of cross section at the top of the Earth's atmosphere, varies not only through the solar cycle (Fröhlich, 2006) but also in a much more complex manner within the solar cycle. The so-called solar dynamo converts polar to toroidal magnetic fields within the Sun that convert kinetic energy into electric currents and magnetic fields. The fuel for this solar dynamo comes from the motions of electrically-charged atomic particles within the solar plasma continuously generates incipient magnetic fields deep within the hot interior of the Sun (Weiss and Tobias, 2000; Weiss and Thompson, 2009). When upwardly mobile magnetic fields generated within the Sun arrive at the boundary that separates the spherical, radiative core of the inner most Sun from the deep shell of convection a thin transition layer which is called tachocline, come in contact with the strong shearing force that arises from the different rates of rotation within radiative core and the convection zone. Due to result of magnetic pressure these toroidal rings of magnetically organized plasma upward and outward through the convective zone that rise like smoke rings one after another. When a portion of any one of these rising rings of bundled magnetic lines of force comes in contact with the photosphere, the toroid is at that point served and pulled apart, exposing two ends of opposite magnetic polarity (Eddy, 2009).

Many of the advances of the past few decades in understanding the effects of the Sun on climate come from direct measurements from space of the fluctuations in solar energy received at the top of the Earth's atmosphere. These seminal measurements of total solar irradiance (TSI) initiated in 1978 and continuing today-give needed substance to modern investigations of the Sun and climate. The total solar irradiance (TSI) varies from minute to minute (Frohlich, 2009), reflecting activity-driven changes on the face of the Sun, from day to day in step with solar rotation and the evolution of solar active regions, with day to day amplitudes of up to about $0.3 \%$; and more important in terms of climate, from year to year with a peak to peak amplitude of about $0.1 \%$, in phase with Schwabe's 11-year sunspot cycle (Eddy, 2009, Frohlich, 2012). In years when the Sun is more active, and more spots are seen, more radiative energy is delivered to the Earth (Baranyi and Pap, 2012). Fig. 2 shows the changes in the total radiation received from the Sun at the top of the Earth's atmosphere through three 11-year solar cycles, starting in 1978 when continuous radiometric measurements of this fundamental parameter were begun. Maxima and minima are in phase with coincident changes in solar activity, with maximum radiation received in years of maximum solar activity (Eddy, 2009). 


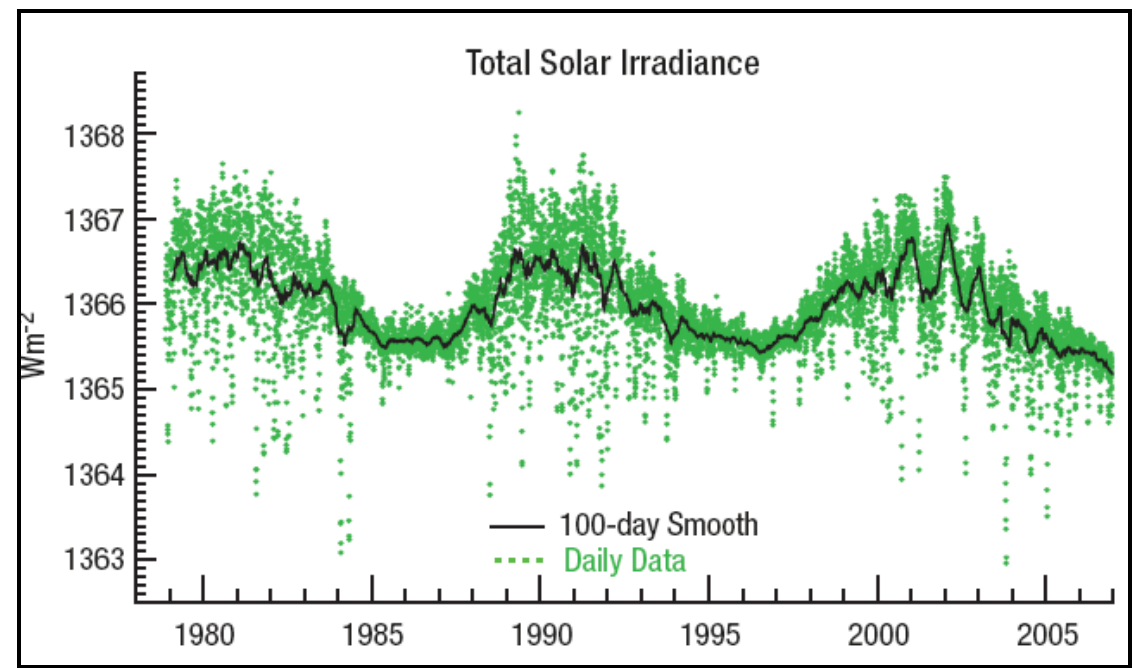

Fig. 2: Changes in the total radiation received from the Sun at the top of the Earth's atmosphere during three 11-year solar cycles (Eddy, 2009)

Solar total (i.e., integrated over all wavelengths) irradiance is the main external source of energy input into the Earth's atmosphere and is thus one of the key parameters of climate models (Krivova et al., 2011). These variations have generally been attributed to the evolution of solar surface magnetic features (Wenzler et al., 2009). Satellite measurements suggested $0.1 \%$ variation of total solar irradiance (TSI) from minimum to maximum of 11 year activity of solar cycle (Haigh, 2003). TSI during the past 35 years shows a solar cycle variation of about $0.1 \%$ and positively correlated with solar activity (Frohlich, 2011; 2012). Recent measurements made by satellites equipped with radiometers in 1990s suggested that the Sun's energy output maybe more variable than was once thought. TSI also changes during the minima period of different solar cycles (Wilson, 1997).

Estimated distribution shows that UV irradiance during the Maunder Minimum was lower by a factor of two at and around wavelength $121.6 \mathrm{~nm}(\mathrm{Ly}-\alpha)$ compared to recent period and up to 5\% -30\% lower in the 150-300 nm region (Krivova and Solanki, 2005). Ultraviolet (UV) irradiance varies by approximately $1.5 \%$ from solar maxima to minima, for 200 to $300 \mathrm{~nm}$ UV (Lean, 1989). Energy changes in the UV wavelengths involved in production and loss of Ozone causing atmospheric effects. The atmospheric pressure level has changed scale height in phase with solar activity during the last four solar cycles. Sometimes UV irradiance increase causes higher ozone production. A number of other influences, unrelated to the Sun itself alter the total amount of solar radiation the Earth receives and how it is distributed over its spherical surface. The non-circularity of the Earth's orbit and a congenital tilt in its axis of rotation continuously modulate the amount of solar energy. Atmospheric absorption and reflection from clouds and aerosols also modulate the radiation (Eddy, 2009; Frohlich, 2012).

\section{Solar Variability and Galactic Cosmic Rays}

Galactic cosmic rays (GCRs) are energetic charged particles mostly having origin outside solar system and traveling throughout the Milky Way galaxy to the Earth's atmosphere. About $89 \%$ of all the incoming cosmic ray particles are simple protons, with 
nearly $10 \%$ being helium nuclei (alpha particles), and slightly under $1 \%$ are heavier elements, electrons (beta particles) constitute about 1\% of galactic cosmic rays (GCRs) (Mewaldt, 2010). Fig. 3 shows how incoming galactic cosmic rays and solar protons penetrate the atmosphere. The energy content of GCRs is an important parameter. The energy densities at the Earth's surface above the energies indicated are, in units of $\mathrm{Jm}^{-3}, \sim 0.05, \sim 0.03,3 \times 10^{-3}$, $10^{-4}$ and $10^{-6}$ (Wolfendale, 1973). By contrast, the total solar irradiance is some $10^{8}$ times greater than that for all GCR (Erlykin and Wolfendale, 2010). GCR flux observed in the Earth's atmosphere exhibits modulation of different periodicities, variability in solar activity, solar electromagnetic radiation in particular, affects the Earth's climate on long run (Gray et al., 2010).

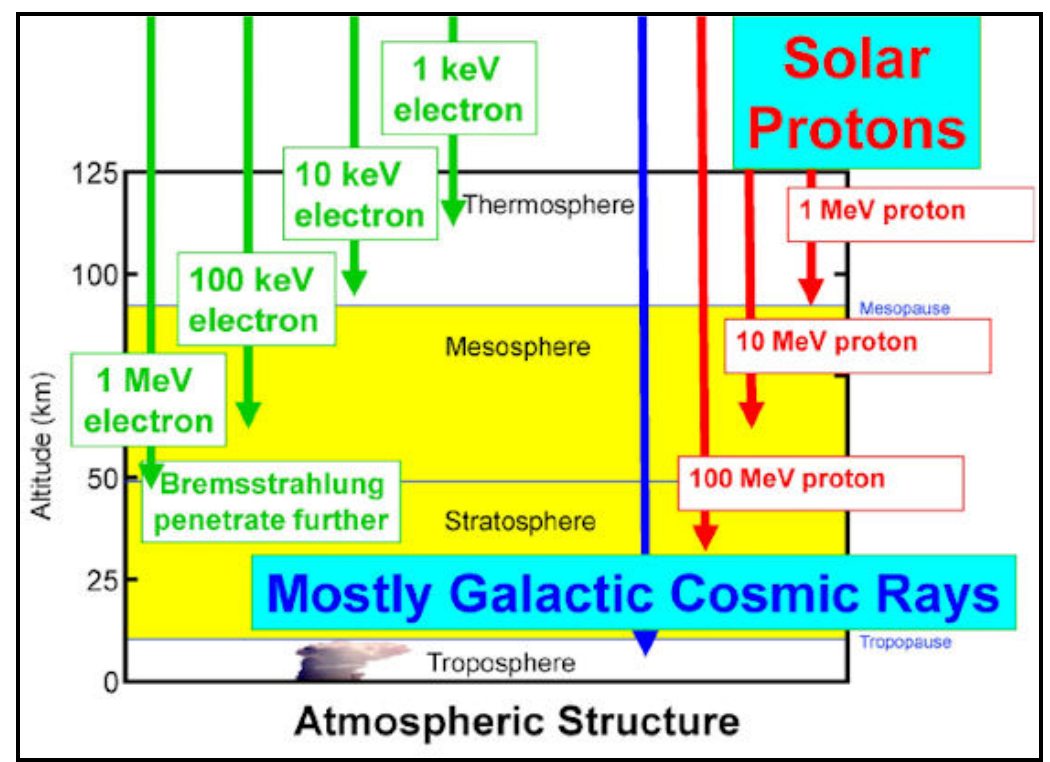

Fig. 3: Schematic of how Galactic Cosmic Rays and Solar Protons penetrate the Earth's Atmosphere.

The primary cause of the solar modulation of cosmic rays is not the level of sunspot activity, but the varying strength of the solar wind. The supersonic out flow of plasma originates in the very hot corona of the Sun and carries ionized particles and magnetic field lines from the Sun. While it is expanding towards the boundary of the solar system, cosmic ray particles interacting with it lose energy. Fig. 4 (http://theresilientearth.com) gives the sketch of interaction between the Heliosphere and cosmic rays which modulate cosmic ray flux by magnetic shielding in the heliosphere. When the solar wind blows heavily cosmic rays are weak, and when the solar wind is in a lull, cosmic rays become strong. The highest velocities in the solar wind are caused by energetic solar eruptions and coronal holes. Strong eruptions (flares and eruptive prominences) avoid sunspot maxima and even occur close to sunspot minima. So sunspots are not a good indicator of solar wind strength (Landscheidt, 1997).

The modulation of GCRs flux occurs during their transport through the heliosphere via four basic processes namely the diffusion, the convection, drift and adiabatic energy losses. Solar magnetic inhomogencity causes scattering and hence diffusion of charged particles. The convection is caused by the out-blowing solar wind and adiabatic energy loss occurs in expanding solar wind. Gradient curvature drift is superimposed on the regular heliospheric magnetic field drift. The charged particles drift along the heliospheric currentsheet, which is a thin magnetic interface between the two heliomagnetic hemispheres. Full 
solution of GCR transport involves a complex and sophisticated 3-D simulation technique. However some approximations are used (Burger et al., 2000; Webber and Higbie, 2003, 2009).

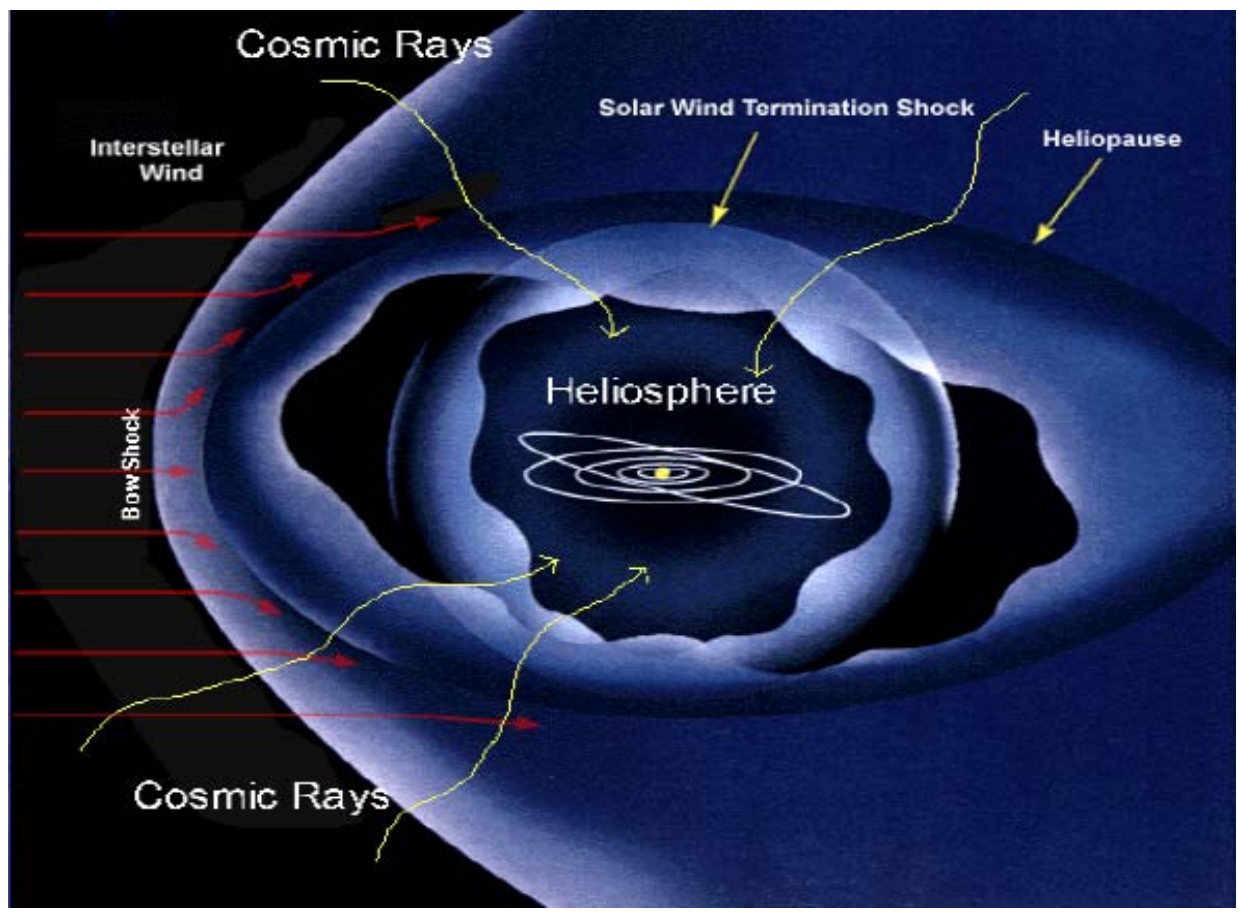

Fig. 4: Modulation of cosmic ray flux by magnetic shielding in heliosphere (http://theresilientearth.com).

GCRs being charged particles are also affected by the geomagnetic field, which puts an additional shielding on the incoming GCR flux. The shielding effects are expressed in terms of the cut-off rigidity, which is the minimum rigidity and energetic charged particle must possess in order to reach the ground at a given location and time (Cooke et al., 1991; Singh et al., 2011). The shielding effect is strongest at the equator ( $70 \mathrm{GV}$ in the Indian region), (Usoskin, 2008). There is almost no cut-off in the geomagnetic polar regions (latitude $>60^{\circ}$ ). Geomagnetic field is stable on the short time scale, but it changes on centurial to millennial time scale (Korte and Constable, 2006). Thus, the incident GCR flux at a given location in the atmosphere and its effects on the atmospheric phenomena and climate will exhibit variation on longer time scale.

The processes by which the Sun's magnetic field modulates GCR fluxes are complex. However, simple anticorrelations (Rouillard and Lockwood, 2004) suggest that much of the variation ( $75 \%)$ of the GCR flux at Earth is explained by the open solar flux. The production rate of ${ }^{10} \mathrm{Be}$ and other cosmogenic radionuclides in the atmosphere is directly proportional to the flux of cosmic ray protons with energy from 1 to $3 \mathrm{GeV}$. On decadal to centennial time scales it is dominated by solar activity; on longer time scales it is dominated by the geomagnetic dipole field (Masarik and Beer, 2009). After production, on the way from the atmosphere to the polar ice caps, ${ }^{10} \mathrm{Be}$ is influenced by changes in climate. However, comparison between Greenland and Antarctic records, as well as modeling, shows that these 
effects are relatively small for production changes on decadal and longer time scales (Heikkilä et al., 2009) but become increasingly more serious for annual resolution. Another issue is the accuracy of ice cores covering thousands of years. Hence, there are several complications in interpreting these indirect measures of solar irradiance.

As cosmic rays, which have positive impact on cloud cover, are strongly modulated by eruptional features of the Sun's activity, the solar contribution to climate change can no longer be considered negligible. There is also a physical explanation of the effect that the secondary ions produced by the cosmic rays serve as condensation nuclei with hygroscopic properties that enhance the formation of clouds (Dickinson, 1975; Barlow and Latham, 1983; Tinsley and Yu, 2003; Siingh and Singh, 2010). A key aspect of the sun's effect on climate is the indirect effect on the flux of Galactic Cosmic Rays (GCRs) into the atmosphere. GCR is an ionizing radiation that supports low cloud formation. As the Sun's output increases the solar wind shields the atmosphere from GCR flux. Consequently the increased solar irradiance is accompanied by reduced low cloud cover, amplifying the climatic effect. Likewise when solar output declines, increased GCR flux enters the atmosphere, increasing low cloudiness and adding to the cooling effect associated with the diminished solar energy.

\section{Solar Variability, Cosmic Rays and Climate}

The topic of possible relations between solar and cosmic ray variability on one hand and the Earth's climate on the other hand is quite an acute and hotly debated (Usoskin, 2012; Ziskin and Shaviv, 2012). It is important to understand how solar variability affects climate, so that human and natural signals may be disentangled in the observational record and thus more reliable predictions of the effects of human activity on future climate may be made. Solar radiation is the main driving source of the Earth's climate (Ziskin and Shaviv, 2012). The other factors responsible for climate changes are change in concentration and circulation of atmosphere and ocean (again controlled by the Sun), processes taking place on/inside the surface of the Earth (both natural and manmade), galactic cosmic rays, manmade changes in the troposphere, etc. (King, 1975). Gray et al. (2005) have discussed each process qualitatively but their quantitative estimate is not available. The role of solar variability as a forcing mechanism of past present and future climate change still raises many questions. Change in solar activity between maxima and minima of 11-year solar cycle during the last three solar cycle only amount to a change of $\sim 0.07 \mathrm{Wm}^{-2}$ in direct radiative forcing at the Earth's surface (Engels and van Geel, 2012).

Galactic cosmic rays entering into the Earth's atmosphere produce ionization which increases with the increasing geomagnetic latitude and decreasing solar activity (Velinov and Mishev, 2007). Change in ionization affects electrical conductivity, nucleation rates in cloud lightning discharges, space weather phenomena etc. (Arnold, 2006; Tinsley, 2008; Tripathi et al., 2008; Singh et al., 2011; Siingh et al., 2011). The cosmic rays control the electrical system of the atmosphere which in turn affects cloud microphysics and radiative transfer of the atmosphere. Both clouds and radiative transfer mechanism change the global temperature and thus affect climate change (Harrison, 2004; Gray et al., 2005). CRs cause ionization in the lower atmosphere, affect the electrical potential and the vertical current flowing through cloud layers, which affect formation and characteristic features of ice clouds and stratiform clouds. Clouds reflect incoming radiation from the Sun and escaping radiation from the Earth. Thus radiative transfer mechanism of the atmosphere is affected, resulting into global temperature change, a major parameter of climate variable. The change in global temperature 
affects formation and intensity and electrodynamics of thunderstorms, which in turn controls atmospheric electrical system, thus forming a closed system.

The solar variability links climate through changes in heat input to the lower atmosphere, changes in ozone concentration in the troposphere and the stratosphere and modulation of galactic and solar cosmic rays. These effects are modulated by long term solar magnetic activity, by changes of the source of galactic and solar cosmic rays and by change of the Earth's magnetic field. The effect of GCRs on climate is through the cloud cover/cloud formation rather than direct energy input into the atmosphere, which is almost $10^{-5}$ times smaller than solar input (Frohlich and Lean, 1997; Siingh and Singh, 2010). There are three probable mechanisms which link solar variability with variations of climate (Carslaw et al., 2002): (a) changes in solar irradiance leading to changes in heat input to the lower atmosphere, (b) changes in solar ultraviolet radiation coupled to changes in ozone concentration affecting the heat budget of the stratosphere, and (c) solar and galactic cosmic rays affecting cloud formation. These effects are modulated by long term solar magnetic activity, by changes of the galactic and solar cosmic rays and by changes of the Earth's magnetic field.

\section{Radiative forcing of climate change:}

Solar irradiance, the flux of the Sun's output directed toward Earth, is Earth's main energy Source (Pagaran, et al., 2011). Fig. 5 reveals the schematic overview showing various climates forcing of the Earth's atmosphere with factors that influence the forcing associated with solar variability through different routes (Gray et al., 2010). The simplest meaning of forcing is just the instantaneous change in the value of the net downward flux. The increase in value from the average value is termed positive forcing. Solar dynamo controls the solar surface magnetic field and CZ field. The shadow effects of CZ field controls solar irradiance which in turn affects processes occurring in the thermosphere, the mesosphere, the stratosphere and the troposphere along with ocean dynamics. Surface field also affects irradiance through the sunspots and faculae. The surface field causes variations in the solar energetic charged particles and cosmic rays which affect processes in the stratosphere and troposphere. Even it causes variation in the geomagnetic field.

In the positive radiative forcing an increase in energy entering the system (or equivalently a decrease in energy leaving the system) tends to warm until the outgoing energy matches the incoming and the net flux becomes zero. The concept of radiative forcing has been found to be a useful tool in analyzing and predicting the response of surface temperature to imposed radiative perturbations. This is because experiments with general circulation models of the coupled atmosphere-ocean system have found that, approximately, the change in globally averaged equilibrium surface temperature, $\mathrm{T}_{\mathrm{g}}$, is linearly related to the radiative forcing-

$$
\Delta \mathrm{T}_{\mathrm{g}}=\lambda \mathrm{RF}
$$

where $\lambda$ is the 'climate sensitivity parameter' and is fairly insensitive to the nature of the perturbation and lies in the range $0.3<\lambda<1.0 \mathrm{~K}\left(\mathrm{Wm}^{-2}\right)^{-1}$ (Haigh, 2007). Thus a calculation of the radiative forcing due to a particular perturbant gives a first-order indication of the 
potential magnitude of its effect on surface temperature without the need for costly general circulation model runs. The large spread in the value of $\lambda$ arises due to different general circulation models, which indicates uncertainties in climate prediction. The radiative forcing is defined at the tropopause with the stratosphere first allowed to adjust to the imposed changes. The presence of ozone in the lower stratosphere increases the downward infrared emission (and thus radiative forcing) both directly through the $9.6 \mu \mathrm{m}$ band and also indirectly through the increase in stratospheric temperatures which it produces (Haigh, 2011). Whether the net effect is positive or negative depends on whether the shortwave or longwave effect dominates and this is determined by the vertical distribution of the ozone change.

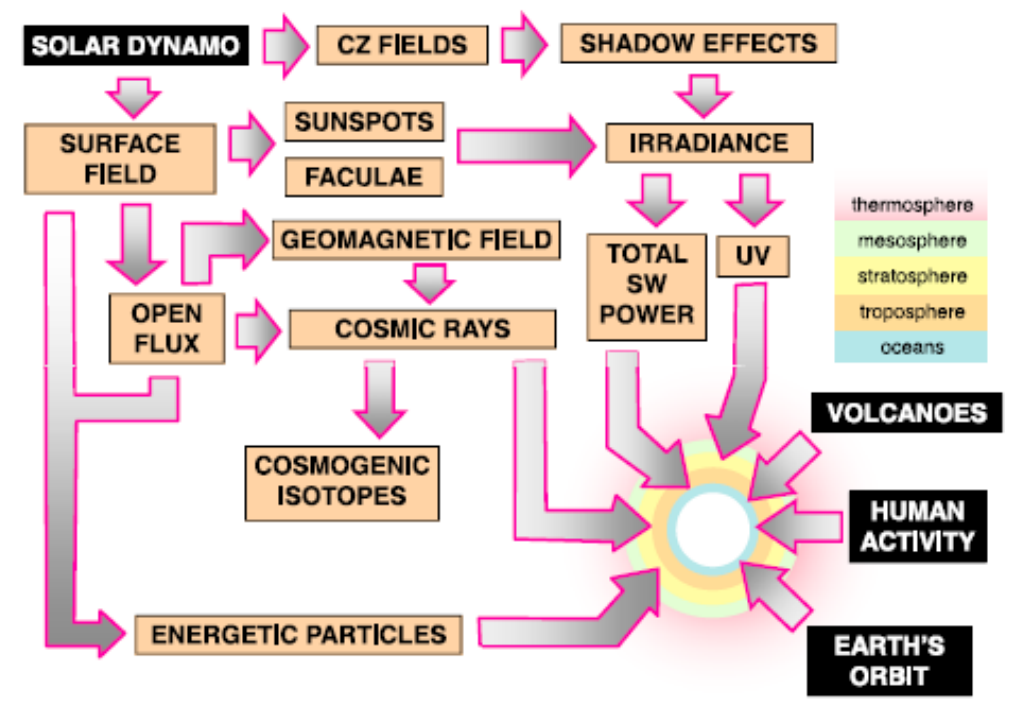

Fig. 5: Schematic overview showing various climate forcing of the Earth's atmosphere, with factors that influence the forcing associated with solar variability (After Gray et al., 2010).

\section{Variations in total solar irradiance:}

Independent space-based solar radiometers universally agree that solar irradiance is higher when the Sun is more active, as indicated by an elevated number of sunspots on its surface (Lean et al., 2005; Shapiro et al., 2011; Vieira et al., 2011; Baranyi and Pap, 2012). Total solar irradiance (TSI) is Earth's dominant energy input exceeding the next largest energy source by nearly $10^{4}$ (Kopp and Lean, 2011; Frohlich, 2012). Total solar irradiance (i.e., the spectrally integrated radiative output) increased " $0.1 \%$ from minima to maxima of the three most recent solar activity cycles (Frohlich, 2011), which peaked near 1980, 1990 and 2001. Also detected with high reliability are shorter-term irradiance changes of as much as $0.3 \%$, associated with the Sun's rotation on its axis (with a period of approximately 27 days). Longer-term irradiance trends that may underlie the activity cycle (and manifest during solar minima) have not yet been reliably detected because the radiometers deployed prior to 2003 lack the needed calibration stability (Frohlich, 2011; Baranyi and Pap, 2012). As a result, different composite records of solar irradiance constructed with diametric assertions of instrumental behavior in independent radiometers differ in their absolute scale and temporal variations, including relative strengths during solar minima (Frohlich and Lean, 2004). A small variation in solar irradiance can produce natural forcing of Earth's climate with global and regional scale responses (IPCC, 2007; Shapiro et al., 2011; Vieira et al., 2011). The most probable value of total solar irradiance representative of solar minimum is $1360.8 \pm 0.5 \mathrm{Wm}^{-2}$ 
lower than the canonical value of $1365.4 \pm 1.3 \mathrm{Wm}^{-2}$ recommended a decade ago (Kopp and Lean, 2011). The observational record of solar irradiance shown in Fig. 6 is the average of three such composite records between 1985 and 2003, extended prior to 1985 with the Physikalisch-Meteorologisches Observatorium Davos (PMOD) composite15 and after 2003 with observations made by the Solar Radiation and Climate Experiment (SORCE) (Kopp et el. 2005). The upper panel is a record of total solar irradiance obtained as an average of three different observational composites. Middle panel shows irradiance variations estimated from an empirical model that combines the two primary influences of facular brightening and sunspot darkening. The symbols indicate direct observations made by the TIM instrument of the SORCE mission, used to determine the relative sunspot and facular components in the model, shown separately in the middle panel. Annual mean sunspot numbers shown in the bottom panel indicate overall levels of solar activity in cycles 21, 22 and 23, with times of minima indicated by the dashed lines (Lean and Woods, 2010; Frohlich, 2012).
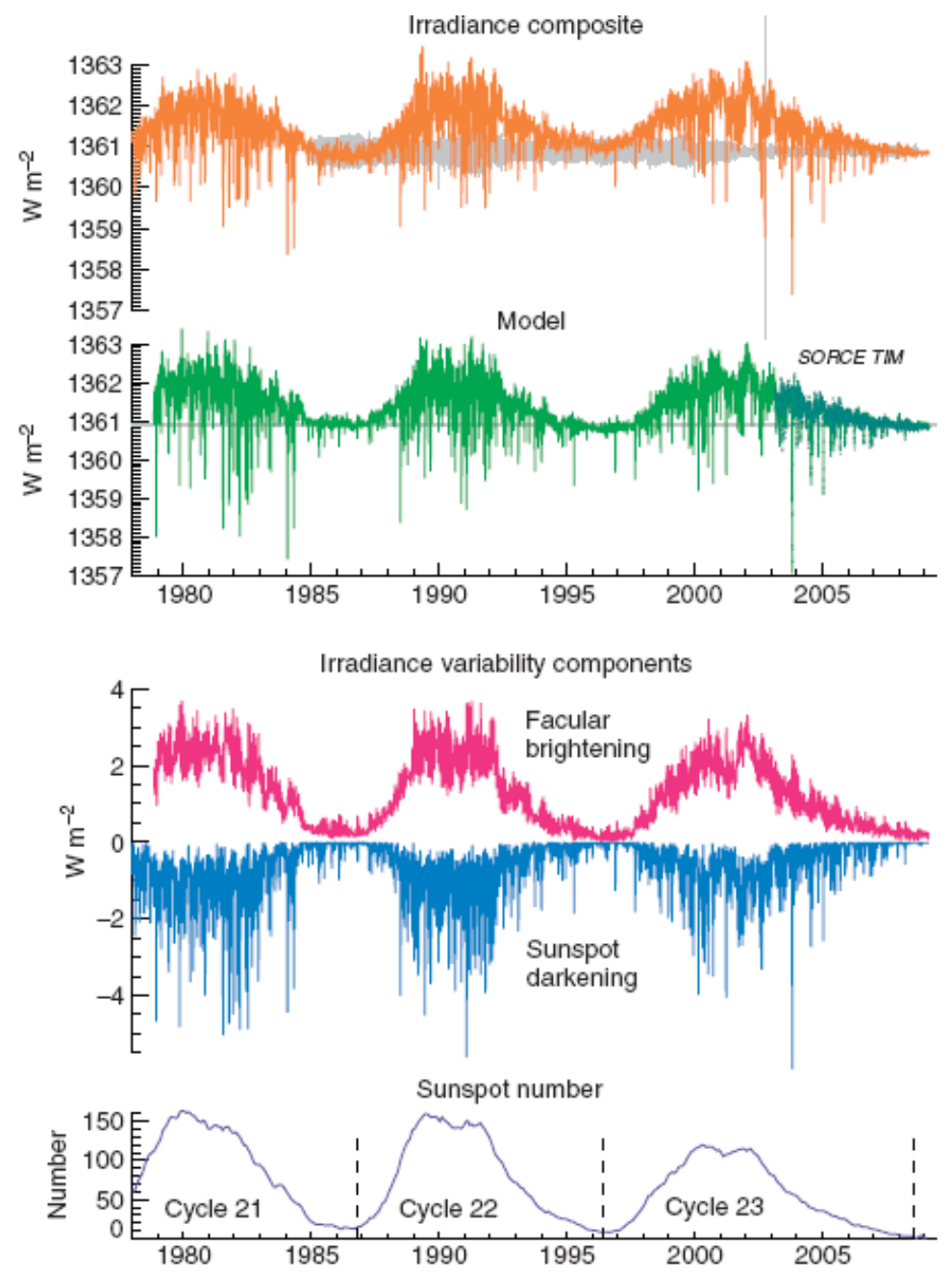

Fig. 6: The average of solar irradiance of three composite records between the year 1985 and 2003 (Lean, 2010). 


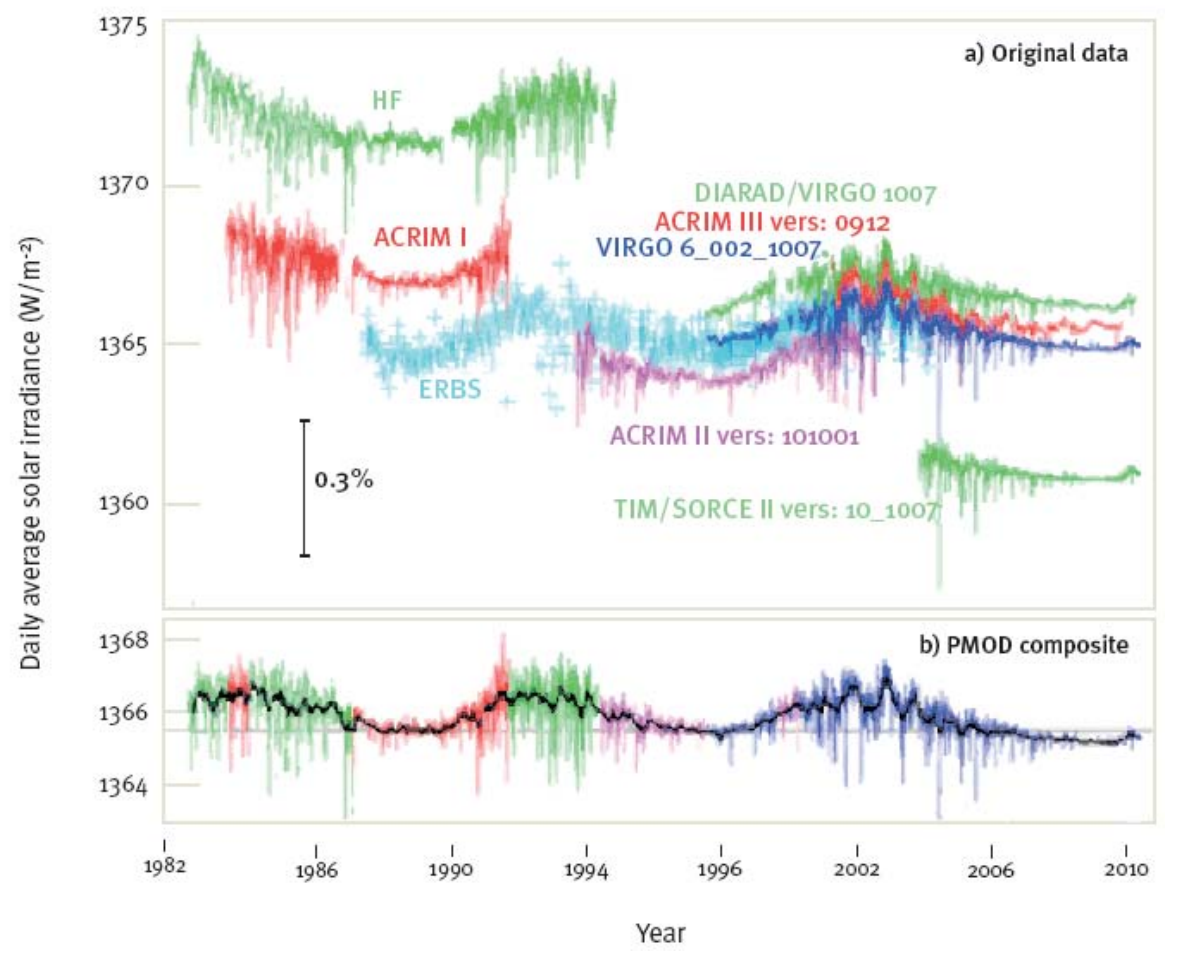

Fig. 7: (a) Daily-averaged total solar irradiance: all measurements made from satellites

(b) Composite of measurements to produce best estimate of TSI (Haigh, 2011)

Direct measurements of total solar irradiance made outside the Earth's atmosphere began with the launch of satellite instruments in 1978. Previous surface-based measurements did not provide sufficient accuracy, as they were subject to uncertainties and fluctuations in atmospheric absorption that may have swamped the small solar variability signal. Most recent reconstructions of total solar irradiance point to only small increase of only about $0.05 \%$ to $0.1 \%$ between Maunder Minimum and the present (Wang et al., 2005; Krivova et al., 2007). Fig. (7a) presents the variation of total solar irradiance from 1978-2010. Data collected from various existing satellite measurements show significant uncertainties related to the calibration of the instruments and their degradation over time. For example, data from the newest instrument, the Total Irradiance Monitor (TIM) on the SORCE satellite, is giving values approximately $5 \mathrm{Wm}^{-2}$ lower than other contemporaneous instruments which disagree among themselves by a few $\mathrm{Wm}^{-2}$. This uncertainty is a serious problem underlying current solar-climate research. The variation in total solar irradiance over the past two 11-year cycles is known to greater accuracy showing $\sim 0.08 \%\left(\sim 1.1 \mathrm{Wm}^{-2}\right)$ peak-to-peak over the solar cycle. Fig. (7b) presents one attempt to composite the measurements into a best estimate. It shows essentially no difference in TSI values between the cycle minima occurring in 1986 and 1996. The results of Willson and Mordinov (2003), however, show an increase in irradiance of $0.045 \%$ between these dates. It is clear that the estimates diverge as they go back in time so that the value of solar radiative forcing over this period is highly uncertain. Furthermore, this plot does not include some estimates which suggest a much larger difference between the present level and that prevailing during the Maunder Minimum in sunspots which occurred during the latter part of the 17th century (Hoyt and Schatten, 1998). 


\section{Galactic cosmic rays and climate:}

Understanding the mechanism of climate changes requires identification of events in high resolution paleo-climatic records and associating them with forcing factors (Denton et al., 2010; Gavin et al., 2011). Solar activity is the main driving source of the Earth's climate (Marsh, 2007; Lofroth, 2008). The other factors responsible for climate changes are change in concentration and circulation of atmosphere and ocean (again controlled by the Sun), processes taking place on/inside the surface of the Earth, galactic cosmic rays, manmade changes in the troposphere, etc. (King, 1975; Usoskin et al., 2008). The experimental data and the results of analysis have revealed a combined effect of geomagnetic dipole changes and long term solar activity variations on climate change. The result obtained supports the idea that GCR fluxes affect climate change (Raspopov, 2009). The cosmogenic radio nuclides including ${ }^{10} \mathrm{Be}$ produced by GCR protons with energy from $1-3 \mathrm{GeV}$ in the atmosphere is dominated by solar activity on decadal to centennial time scales whereas on longer time scales it is dominated by the geomagnetic dipole field (Masarik and Beer, 2009). Marsh and Svensmark (2000) showed a positive correlation between low cloud cover and GCRs over the period 1983 - 2005, which was contradicted by many workers (Sun and Bradley, 2002; Laut, 2003; Gray et al., 2010). Sloan and Wolfendale (2008) reported that less than 23\% of the 11 year cycle in cloud could be attributed to the solar modulation of GCRs. Siingh and Singh (2010) and Siingh et al. (2011) reviewed the relation between GCR and cloud cover and concluded that more data analysis and modeling studies are required either to accept or reject the GCR and cloud cover hypothesis.,

The GCR effects on cloud cover was also reached during Forbush decrease (Fd) in GCR flux (Kniventon, 2004; Todd and Kniventon, 2004; Harrison and Stephenson, 2006; Kristjansson et al., 2008) caused by the transient effect of coronal mass ejections that pass over or close to the Earth. In all these studies no significant correlation was observed. Svensmark et al. (2009) reported large (upto 7\%) global cloud cover decreases, as detected by a number of satellites following Fds in GCR fluxes. The results are based on only few large Fds when satellite cloud data is available. In a very detailed correlation analysis of six Fds and allowing for different lags between cosmic ray flux and cloud cover, no significant effect of cosmic rays on low cloud cover could be found (Calogovic et al., 2010). Significance of these studies has also been discussed by Lockwood (2010).

The long term analysis of satellite data for cloud measurements suffers the calibration issue. To avoid it, surface based clouds determination using solar radiation measurements (Duchon and O’Malley, 1999; Calbo et al., 2001; Harrison et al., 2008) were used for cloud cover over fifty years of UK data and it was found that days with high cosmic rays had greater odds of being overcast and on average coincided with days having a $2 \%$ increased diffused fraction (Harrison and Stephenson, 2005) which is implied slightly increased cloud cover (Dengel et al., 2009). As the linear correlation was less than $0.2 \%$ of the variance in cloud cover, a non-linear relation was proposed. Inspite of non-encouraging correlation between GCR and cloud cover, the GCR-cloud cover hypothesis is gaining momentum because microphysical processes linking GCR included ionization and cloud are becoming clear (Yu, 2002; Harrison and Ambaum, 2008; Usoskin and Kovatlsov, 2008; Carslaw, 2009; Nicoll and Harrison, 2009; Harrison and Usoskin, 2010). Gurevich et al. (2009) and Chubenko et al. (2009) have shown cosmic ray induced lightning using experimental 
measurements supporting the GCR induced cloud cover hypothesis. However, it is not yet possible to identify the percentage of lightning discharges triggered by GCRs.

To understand the nature of the physical mechanism relating cosmic ray-cloudclimate hypothesis, an experimental facility at CERN has been setup which is known as CLOUD (Cosmics Leaving OUtdoor Droplets) (Kirkby, 2007). The exploratory measurements have provided suggestive evidence for ion-induced nucleation or ion-ion recombination as sources of aerosol particles from trace sulphuric acid vapour at typical atmospheric concentration (Duplissy et al., 2010). Thus preliminary results of CLOUD experiment are also showing encouraging results in the positive direction of GCR-cloud hypothesis.

\section{Summary}

In this paper, we have briefly summarized our present understanding of the terrestrial climate as affected by solar variability and galactic cosmic rays (GCRs) and associated processes. The variation of solar irradiance on time scales from hours to billions of years depends on solar activity which is dependent on various processes operating inside/on the surface of the Sun. It is also affected by the rotation of the Sun, the precession of the Earth and the obliquity of the Earth's rotational axis and changes due to the eccentricity of Earth's orbit. Apart from the above, geomagnetic field strength also play a key role in modulation of cosmic rays intensity.

The Sun's magnetic field varies in a complex manner, including the well known sunspot cycle of $\sim 11$ years periodicity and longer period modulations. The total solar irradiance and its spectral distribution vary through the solar cycle as well as from one solar cycle to the other solar cycle in a complex manner. The irregular behavior of long term solar activity contains random components and it is difficult to model it using a combination of quasi-periodic processes. Different models are being developed utilizing recent results of observations to estimate the variability within the irradiance spectrum and its implications in the development of solar dynamo models and solar terrestrial studies are being assessed.

The GCR flux reaching the Earth's magnetosphere is the function of latitude, longitude and altitude due to modulation in the interplanetary space by the solar wind and in the magnetosphere by the geomagnetic field. As a result ionization produced by GCR becomes a function of latitude, longitude and altitude. Consequences of ionization are the cloud formation which affects climate. Although data show association between GCR flux and cloud cover at longer time scale, the correlation in individual cases needs further study. However, the emergence of physical processes linking GCR produced ionization and cloud nucleation puts additional importance of GCR-cloud cover hypothesis. Even initial results of CLOUD experiments of CERN support this hypothesis.

Finally, it is noted that the studies relating solar variability-GCR flux-climate variability has emerged from its beginnings of almost purely investigation of statistical relationships to a solid scientific field that involves solar physicists, atmospheric physicists and climate scientists. A large number of problems have been solved and many more have been posed which require consistent efforts in data handling and simulations. 
Acknowledgements: AKS is thankful to Indian Space Research Organization (ISRO) for providing financial support as research project under CAWSES phase II program. Authors are also thankful to reviewer for providing scientific comments to improve the quality of the manuscript.

\section{References}

Ahluwalia, H. S. and Jackiewicz, J. (2012) Sunspot cycle 23 decent to an unusual minimum and forecasts for cycle 24 activity. Adv. Space Res., v. 50, pp. 662-668.

Arnold, F. (2006) Atmospheric aerosol and cloud condensation nuclei formation: A possible influence of Cosmic rays? Space Sci. Rev., v.125, pp.169-186.

Baranyi, T. and Pap, J. M. (2012) Active region properties and irradiance variations. Adv. Space Res., v. 50, pp. 676-682.

Bard, E., Raisbeck, G.M., Yiou, F. and Jouzel, J. (1997) Solar modulation of cosmogenic nuclide production over the last millennium: comparison between ${ }^{14} \mathrm{C}$ and ${ }^{10} \mathrm{Be}$ records. Earth Planet. Sci. Lett., v. 150, pp. 453-462.

Barlow, A. K., and Latham, J. (1983) A laboratory study of the scavenging of submicro aerosol by charged raindrops. Quart. J.R. Met. Soc., v. 109, pp. 763.

Beer, J., (2000) Long-term indirect indices of solar variability. Space Sci. Rev., v. 94, pp. 53-66.

Beer, J., Blinov, A., Bonani, G., Finkel, R.C., Hofmann, H.J. Finkel, R. C., Lehmann, B. Oeschger, H., Sigg, A., Schwander, J., Staffelbach, T. Stauffer, B., Suter, M. (1990) Use of ${ }^{10}$ Be in polar ice to trace the 11 -year cycle of solar activity. Nature, v. 347, pp. 164-166.

Berger, A., Loutre, M.F. and Crucifix, M. (2003) The Earth's climate in the next hundred thousand years. Surv. Geophys., v. 24, pp. 117-138.

Brueckner, G. E., Edlow, K. L., Floyd, L. E., Lean, J. and Vanhoosier, M. E. (1993) The Solar Ultraviolet Spectral Irradiance Monitor (SUSIM) experiment onboard the Upper Atmosphere Research Satellite (UARS). J. Geophys. Res., v. 98, pp. 10695-10711.

Burger, R. A., Potgieter, M.S. and Heber, B. (2000) Rigidity dependence of cosmic ray proton latitudinal gradients measured by the Ulysses spacecraft: Implications for the diffusion tensor. J. Geophys. Res., v. 105, pp. 27,447-27,456.

Calbó, J., Gonzalez, J.A. and Pagès, D. (2001) A method for skycondition classification from ground-based solar radiation measurements. J. Appl. Meteorol., v. 40, pp. 2193-2199.

Calogovic, J., Albert, C., Arnold, F., Beer, J., Desorgher, L. and Flueckiger, E.O. (2010) Sudden cosmic ray decreases: No change of global cloud cover. Geophys. Res. Lett., v. 37, L03802, doi: 10.1029/2009GL041327.

Carslaw, K. (2009) Cosmic rays, clouds and climate. Nature, v. 460, pp. 332-333.

Carslaw, K.S., Harrison, H.G. and Kirkby, J. (2002) Cosmic rays, clouds and climate. Science, v. 298, pp. 17321737.

Cattaneo, F. (1999) On the origin of magnetic field in the quiet photosphere. Astrophys. Journal, v. 515, pp. L39-L42.

Chubenko, A.P., Karashtin, A.N., Ryabov, V.A., Shepetov, A.L., Antonova, V.P., Kryukov, S. V., Mitko, G. G., Naumov, A. S., Pavljuchenko, L. V., Ptitsyn, M. O., Shalamova, S. Ya., Shlyugaev, Yu. V., Vildanova, L. I., Zybin, K. P. and Gurevich, A. V. (2009) Energy spectrum of lightning gamma emission. Phys. Lett. A, pp. 373-2953, doi:10.1016/j.physleta.2009.06.031.

Cooke, D. J., Humble, J.E., Shea, M.A., Smart, D.F., Lund, N., Rasmussen, I.L., Byrnak, B., Goret, P. and Petrou, N. (1991) On cosmic-ray cutoff terminology. Il Nuovo Cimento, v. 14C, pp. 213-234.

Dengel, S., Aeby, D. and Grace, J. (2009) A relationship between galactic cosmic radiation and tree rings. New Phytol., v. 184, pp. 545-551.

Denton, G.H., Anderson, R.F., Toggweiler, J.R., Edwards, R.L., Schaefer, J.M. and Putnam, A.E. (2010) The last glacial termination. Science, v. 328, pp. 1652-1656.

Dewitte, S., Crommelynck, D., Mekaoui, S. and Joukoff, A. (2004) Measurement and uncertainty of the long-term total solar irradiance trend. Sol. Phys., v. 224, pp. 209-216.

Dickinson, R. E. (1975) Solar variability and the lower atmosphere. Bull. Am. Meteorol. Soc., v. 56, pp. 1240.

Duchon, C.E. and O’Malley, M.S. (1999) Estimating cloud type from pyranometer observations. J. Appl. Meteorol., v. 38, pp. 132-141. 
Duplissy, J., et al. (2010) Results from the CERN pilot CLOUD experiment. Atmos. Chem. Phys. Discuss., v. 9, pp. $18,235-18,270$.

Eddy, J.A. (1976) The Maunder Minimum. Science, v. 192, pp. 1189-1202.

Eddy, J.A. (2009) The Sun, the Earth, and Near-Earth Space - A Guide to the Sun-Earth System. NASA NP2009-1-066-GSFC.

Engels, S. and van Geel, V. (2012) The effects of changing solar activity on climate: contributions from palaeoclimatological studies. J. Space Weather Space Clim., v. 2, A09.

Erlykin, A.D., and Wolfendale, A.W. (2010) Long term time variability of cosmic rays and possible relevance to the development of life on Earth. Surv. Geophys. v. 31, pp. 383-398.

Fröhlich, C. (2006) Solar irradiance variability since 1978: Revision of the PMOD composite during solar cycle 21. Space Sci. Rev., v. 125, pp. 53-65.

Frohlich, C. (2009) Evidence of a long term trend in solar irradiance. Astron. Astrophys., v. 501, pp. 27-30.

Frohlich, C. (2011) Total solar irradiance: What have we learned from the last three cycles and the recent minimum? Space Sci. Rev., doi 10.1007/s11214-011-9780-1.

Frohlich, C. (2012) Total Solar Irradiance Observations. Surv. Geophys., v. 33, 453-473.

Frohlich, C., and Lean, J. (1997) Total solar irradiance variation in new eyes to see inside the sun and stars. In: Deubner et al. (eds.), Proc. IAU Symposium, Kyoto, 89, 185, Kluwer.

Frohlich, C. and Lean, J. (2004) Solar radiative output and its variability: evidence and mechanisms. Astron. Astrophys. Rev., v. 12, pp. 273-320.

Gavin, D. G., Henderson, A.C.G., Westover, K.S., Fritz, S.C., Walker, I.R., Leng, M.J. and Hu, F.S. (2011) Abrupt Holocene climate change and potential response to solar forcing in western Canada. Quaternary Science Reviews, v. 30, pp. 1243-1255.

Gray, L.J., Beer, J., Geller, M., Haigh, J.D., Lockwood, M., Matthes, K. Cubasch, U., Fleitmann, D., Harrison, G., Hood, L., Luterbacher, J., Meehl, G.A., Shindell, D., van Geel, B. and White, W. (2010) Solar influences on climate. Rev. Geophys., v. 48, RG4001, doi:10.1029/2009RG000282.

Gray, L.J., Haigh, J.D. and Harrison, R.G. (2005) A review of the influence of solar changes on the Earth's climate. Hadley Centre Technical report no. 62.

Gurevich, A.V., Karashtin, A.N., Ryabov, V.A., Chubenko, A.P. and Shepetov, A.L. (2009) Effects of cosmic rays and runaway breakdown on thunderstorm discharges. Physics Uspekhi, v. 52, pp. 735.

Haigh, J.D. (2003) The effects of solar variability on the Earth's climate. Philos. Trans. R. Soc. London, Ser. A, v. 361, pp. 95-111.

Haigh, J.D. (2007) The Sun and the Earth’s Climate, Living Rev. Solar Phys., v. 4, pp. 2.

Haigh, J.D. (2011) Solar influences on climate. Imperial College, London, 2011.

Hanslmeier, A. (2007) The Earth's Atmosphere and Climate. Astrophysics and Space Science Library, v. 347, pp. 123-142.

Harrison, R.G. (2004) The global atmospheric electric circuit and climate. Surv. Geophys., v. 25, pp. 441-484.

Harrison, R.G., and Stephenson, D.B. (2005) Empirical evidence for a nonlinear effect of galactic cosmic rays on clouds. Proc. R. Soc. A, v. 462, pp. 1221-1233.

Harrison, R.G. and Stephenson, D.B. (2006) Empirical evidence for a nonlinear effect of galactic cosmic rays and cloud. Proc. Roy. Soc., v. 462, pp. 1221-1233.

Harrison, R.G. and Ambaum, M.H.P. (2009) Observed atmospheric electricity effects on clouds. Environ. Res. Lett., v. 4, doi:10.1088/1748-9326/4/1/014003.

Harrison, R.G. and Usoskin, I. S. (2010) Solar modulation in surface atmospheric electricity. J. Atmos. Sol. Terr. Phys., v. 72, pp. 176-182.

Harrison, R.G., Chalmers, N. and Hogan, R.J. (2008) Retrospective cloud determinations from surface solar radiation measurements. Atmos. Res., v. 90, pp. 54-62.

Hathaway, D. (2010) The Solar Cycle. Living Rev. Solar Phys., 7, lrsp-2010.

Hathaway, D. H., and Wilson, R.M. (2004) What the Sunspot Record Tells Us About Space Climate? Solar Phys., v. 224, pp. 5-19.

Heikkilä, U., Beer, J. and Feichter, J. (2009) Meridional transport and deposition of atmospheric ${ }^{10}$ Be. Atmos. Chem. Phys., v. 9, pp. 515-527.

Hoyt, D.V. and Schatten, K.H. (1998) Group sunspot numbers: A new solar activity reconstruction. Solar Phys., v. 179, pp. 189-219.

Juckett, D.A. (2000) Solar activity cycles, north/south asymmetries, and differential rotation associated with solar spin-orbit variations. Sol. Phys., v. 191, pp. 201-226.

King, J.W. (1975) Sun-weather relationships. Aeronaut. Astronaut., v. 13, pp. 10-19.

Kirkby, J. (2007) Cosmic rays and climate. Surv. Geophys., v. 28, pp. 333-375.

Klotz, I. (2010) A new era of space weather forecasting. Space Weather, v. 8, S05003. doi:10.1029/2010SW000587. 
Kniveton, D.R. (2004) Precipitation, cloud cover and Forbush decreases in galactic cosmic rays. J Atmos SolarTerr Phys., v. 66, pp. 1135-1142.

Kopp, G., Lawrence, G. and Rottman, G. (2005) The total irradiance monitor (TIM): science results. Solar Phys., v. 230, pp. 129-139.

Kapp, G., and Lean, J.L. (2011) A new, lower value of total solar irradiance: Evidence and climate significance. J. Geophys. Res., v. 38, L01706, doi: 10.1029/2010GL045777.

Korte, M., and Constable, C.G. (2006) Centennial to millennial geomagnetic secular variation. Geophys. J. Int., v. 167, pp. 43-52.

Kristjánsson, J.E., Stjern, C.W., Stordal, F., Fjaeraa, A.M., Myhre, G. and Jonasson, K. (2008) Cosmic rays, cloud condensation nuclei and clouds-A reassessment using MODIS data. Atmos. Chem. Phys., v. 8, pp. 7373-7387.

Krivova, N.A., and Solanki, S.K. (2005) Reconstruction of solar UV irradiance. Adv. Space Res., v. 35, pp. 361364.

Krivova, N.A., Solanki, S.K., Fligge, M. and Unruh, Y.C. (2003) Reconstruction of solar irradiance variations in cycle 23: Is solar surface magnetism the cause? Astron. Astrophys., v. 399, pp. L1-L4, doi:10.1051/00046361:20030029.

Krivova, N.A., Balmaceda, L. and Solanki, S.K. (2007) Reconstruction of solar total irradiance since 1700 from the surface magnetic flux. Astronom. Astrophys., v. 467, pp. 335-346.

Krivova, N.A., Solanki, S.K. and Schmutz, W. (2011) Solar total irradiance in cycle 23, Astron. Astrophys., v. 529, A81.doi:10.1051/0004-6361/201016234.

Landscheidt, T. (1997) Klimavorhersage mit astronomischen Mitteln? Fusion, v. 18, pp. 58.

Laut, P. (2003) Solar activity and terrestrial climate: An analysis of some purported correlations. J. Atmos. Sol. Terr. Phys., v. 65, pp. 801-812.

Lofroth, E. (2008) Are solar activity and cosmic rays important factors behind climate change? pp. 17.

Lean, J. (1989) Contribution of Ultraviolet Irradiance Variations to Changes in the Sun's Total Irradiance Science. Science, v. 244, pp. 197-200.

Lean, J. (1997) The Sun's variable radiation and its relevance for Earth. A. Rev. Astrl. Astrophys., v. 35, pp. 3367.

Lean, J. (2010) Cycles and trends in solar irradiance and climate. John Wiley \& Sons, Ltd, 1.

Lean, J. and Woods, T.N. (2010) Solar total and spectral irradiance: measurements and models. In: Evolving Solar Physics and the Climates of Earth and Space, K., Schrijver, G., Siscoe (eds.) Cambridge, UK: Cambridge University Press.

Lean , J., Rottman, G. Harder, J. and Kopp, G. (2005) SORCE contributions to new understanding of global change and solar variability. Solar Phys., v. 230, pp. 27-53. doi:10.1007/s11207-005-1527-2.

Lockwood, M. (2010) Solar change and climate: An update in the light of the current exceptional solar minimum. Proc. R. Soc. A, v. 466, pp. 303-329.

MacGorman, D.R., and Rust, W.D. (1998) The Electrical Nature of Storms. Oxford Univ. Press, New York.

Marsh, N.D. (2007) Influence of solar activity cycles on Earth’s climate. In: Space Weather, J. Lilensten (ed.), Springer, pp. 83-94.

Marsh, N.D. and Svensmark, H. (2000) Low cloud properties influenced by cosmic rays. Phys. Rev. Lett., v. 85, pp. 5004-5007.

Masarik, J., and Beer, J. (2009) An updated simulation of particle fluxes and cosmogenic nuclide production in the Earth’s atmosphere. J. Geophys. Res., v. 114, D11103.

Mewaldt, R. A. (2010) Cosmic Rays. California Institute of Technology. http://www.srl.caltech.edu/personnel/dick/cos_encyc.html

Nicoll, K.A., and Harrison, R.G. (2009) Vertical current flow through extensive layer clouds. J. Atmos. Sol. Terr. Phys., v. 71, pp. 1219-1221.

Parker, E.N. (1957) Newtonian development of the dynamical properties of ionized gases of low density. Phys. Rev., v. 107, pp. 92.

Pagaran, J., Harder, J.W., Weber, M., Floyd, L.E. and Burrows, J.P. (2011) Intercomparison of SCIAMACHY and SIM vis- IR irradiance over several solar rotational timescales. Astron. Astrophys., v. 528, A67, doi:10.1051/0004-6361/201015632, 2011.

Radick, R.R. (2004) Long-Term Solar Variability: Evolutionary Time Scales. Geophys. Mono., v. 141, American Geophysical Union, 10.1029/141GM02. 
Raspopov, O.M., Dergachev, V.A., Dmitriev, P. V. and Guskova, G. (2009) Effect of long term variability of galactic cosmic ray fluxes on climatic parameters. Bulletin Russ. Academy of Sci.: Physics, v. 73, pp. 375377.

Roble, R.G. and Tzur, I. (1986) The global atmospheric-electrical circuit: The Earth's Electrical Environment. Vol. Studies in Geophysics. National Academy Press, Washington, DC, pp. 206-231.

Rottman, G.J., Woods, T.N. and Sparn, T.P. (1993) Solar stellar irradiance comparison experiment: instrument design and operation. J. Geophys. Res., v. 98, pp. 10667-10678.

Rouillard, A., and Lockwood, M. (2004) Oscillations in the open solar magnetic flux with period 1.68 years: Imprint on galactic cosmic rays and implications for heliospheric shielding. Ann. Geophys., v. 22, pp. 4381-4395.

Schussler, M., Schmitt, D. and Ferriz-Mas, A. (1997) Long-term Variation of Solar Activity by a Dynamo Based on Magnetic Flux Tubes. In: 1st Advances in Solar Physics Euroconference: Advances in the Physics of Sunspots, Schmieder, B., del Toro Iniesta, J.C., Vazquez, M. (eds.), v. 118 of ASP Conference Series, pp. 39-44, Astronomical Society of the Pacific, San Francisco.

Schwenn, R. (2006a) Solar wind sources and their variations over the solar cycle. Space Sci Rev., v. 124, pp. 51-76.

Schwenn, R. (2006b), Space weather: the solar perspective. Living Rev Solar Phys, v. 3, lrsp-2006-2.

Shapiro, A.I., Schmutz, W., Rozanov, E., Schoell, M., Haberreiter, M., Shapiro, A.V. and Nyeki, S. (2011) A new approach to long term reconstruction of the solar irradiance leads to large historical solar forcing. Astron. Astrophys., v. 529, id.A67, 8. 10.1051/0004-6361/201016173.

Siingh, D., Singh, R.P., Singh, A.K., Kulkarni, M.N., Gautam, A.S. and Singh, A.K. (2011) Solar activity, Lightning and Climate. Sur. Geophys., v. 32, pp. 659-703.

Siingh, D., and Singh, R.P. (2010) The role of cosmic rays in the Earth's atmospheric processes. Pramana Journal of Physics, v. 74, pp. 153-168.

Singh, A.K. and Singh, R.P. (2003) Space weather-causes, consequences and predictions. Indian J Phys., v. 77B(6), pp. 611-616.

Singh, A.K., Siingh, D. and Singh, R.P. (2010) Space Weather: Physics, Effects and predictability, Sur. Geophys., v. 31, pp. 581-638.

Singh, A.K., Siingh, D. and Singh, R.P. (2011) Impact of galactic cosmic rays on Earth's atmosphere and Human Health. Atmos. Enviorn., v. 45, pp. 3806-3818.

Sloan, T. and Wolfendale, A.W. (2008) Testing the proposed causal link between cosmic rays and cloud cover. Environ, Res. Lett., v. 3, 024001, doi:10.1088/1748-9326/3/2/024001.

Solanki, S.K. (2002) Solar variability and climate change: Is there a link? Astron. Geophys., v. 43, pp. 5.9-5.13.

Solanki, S.K., Krivova, N.A. and Wenzler, T. (2005) Irradiance models. Adv. Space Res., v. 35, pp. 376.

Stuiver, M., and Quay, P.D. (1980) Changes in Atmospheric Carbon-14 Attributed to a Variable Sun. Science, v. 207, pp. 11-19.

Sun, B., and Bradley, R.S. (2002) Solar influences on cosmic rays and cloud formation: A reassessment. J. Geophys. Res., v. 107, p. 4211.

Svensmark, H., Bondo, T. and Svensmark, J. (2009) Cosmic ray decreases affect atmospheric aerosols and clouds. Geophys. Res. Lett., v. 36, pp. L15101.

Tinsley, B.A. (2008) The global atmospheric electric circuit and its effects on cloud microphysics. Rep. Prog. Phys., v. 71, pp. 066801-066832.

Tinsley, B.A., and Yu, F. (2003) Atmospheric ionization and clouds as links between solar activity and climate. In: Frolich, C., Hudson, H., Kuhn, J., McCormack, J., North, J., Pap, J., Sprigg, W., Wu, S.T. (eds.), AGU monograph: solar variability and its effects on the earth's atmospheric and climate system, pp. 1-19.

Todd, M.C., and Kniveton, D.R. (2004) Short-term variability in satellite-derived cloud cover and galactic cosmic rays: an update. J. Atmos. Sol. Terr. Phys., v. 66, pp. 1205-1211.

Tripathi, S.N., Michael, M. and Harrison, R.G. (2008) Profiles of Ion and Aerosol Interactions in Planetary Atmospheres. Space Sci. Rev., v. 137, pp.193-211.

Usoskin, I.G. (2008), Living Reviews, Sol. Phys., v. 5, 3.

Usoskin, I.G., and Kovaltsov, G.A. (2008) Cosmic rays and climate of the Earth: possible connection. C.R. Geoscience, v. 340, pp. 441-450.

Usoskin, I.G. (2012) Solar variability, cosmic rays and climate: what's up? Adv. Space Res., v. 50, pp. 655.

Velinov, P.I.Y. and Mishev, A. (2007) The induced Ionization by Solar Cosmic Rays in the Earth AtmosphereCORSIKA code simulations. Comptes rendus de l'Académie bulgare des Sciences, v. 60, pp. 493-500.

Vieira, L.E.A., Solanki, S.K., Krivova, N.A. and Usoskin, I. (2011) Evolution of the solar irradiance during the Holocene. Astron. Astrophys. v. 531, id.A6, 10.1051/0004-6361/201015843.

Vita-Finzi, C. (2008) The Sun: A User’s Manual. Springer; doi:10.1007/978-1-4020-6881-2. 
Wang, Y.M., Lean, J.L. and Sheeley, N.R. (2005) Modeling the Sun's magnetic field and irradiance since 1713. Astrophysical Journal, v. 625, pp.522-538.

Weart, S. (2006) The Discovery of Global Warming. In: Spencer Weart, American Institute of Physics. http://www.aip.org/history/climate/index.html. Retrieved 2007-04-14.

Webber, W.R. and Higbie, P.R. (2003) Production of cosmogenic $B_{e}$ nuclei in the Earth's atmosphere by cosmic rays: Its dependence on solar modulation and the interstellar cosmic ray spectrum. J. Geophys. Res., v. 108, pp. 1355.

Webber, W.R. and Higbie, P.R. (2009) Galactic propagation of cosmic ray nuclei in a model with an increasing diffusion coefficient at low rigidities: A comparison of the new interstellar spectra with Voyager data in the outer heliosphere. J. Geophys. Res., v. 114, A02103.

Weiss, N.O. and Tobias, S.M. (2000) Physical causes of solar activity. Space Sci. Rev., v. 94, pp. 99-112.

Weiss, N.O. and Thompson, M.J. (2009) The Solar Dynamo. Space Sci. Revs., v. 144, pp. 53-66.

Wenzler, T., Solanki, S.K. and Krivova, N.A. (2009) Reconstructed and measured total solar irradiance: Is there a secular trend between 1978 and 2003? Geophys. Res. Lett., v. 36, L11102, doi:10.1029/2009GL037519.

Willson, R. (1997) Total solar irradiance trend during solar cycles 21 and 22. Science, v. 277, pp. 1963-1965.

Willson, R.C., and Mordvinov, A.V. (2003) Secular total solar irradiance trend during solar cycles 21-23, Geophys. Res. Lett., v. 30, pp. 1199.

Willson, R.C., and Hudson H.S. (1988), Solar Luminosity Variations in Solar Cycle 21. Nature, v. 332, pp. 810812.

Willson, R.C. and Hudson, H.S. (1991) The Sun's luminosity over a complete solar cycle. Nature, v. 351, pp. 42-44.

White, Q., Kopp, G., Snow, M. and Tapping, K. (2011) The solar cycle 23-24 Minimum. A benchmark in solar variability and effects in the heliosphere. Solar. Phys., v. 274, pp. 159-162.

Wolfendale, A.W. (1973) Cosmic rays at ground level. In: Wolfendale AW (ed.) Inst. of Physics, p 1.

$\mathrm{Yu}, \mathrm{F}$. (2002) Altitude variations of cosmic-ray induced production of aerosols: Implications for global cloudiness and climate. J. Geophys. Res., v. 107, pp. 1118.

Ziskin, S., and Shaviv, N.J. (2012) Quantifying the role of solar radiative forcing over the $20^{\text {th }}$ century. Adv. Space Res., v. 50, pp. 762-776.

(Received: 02.09.13; Accepted: 13.01.14) 